\title{
A global alliance declaring war on cassava viruses in Africa
}

\author{
James Legg • Eklou Attiogbevi Somado • Ian Barker • Larry Beach • Hernan Ceballos • Willmer Cuellar • \\ Warid Elkhoury • Dan Gerling • Jan Helsen • Clair Hershey • Andy Jarvis • Peter Kulakow • Lava Kumar • \\ Jim Lorenzen • John Lynam • Matthew McMahon • Gowda Maruthi • Doug Miano • Kiddo Mtunda • \\ Pheneas Natwuruhunga • Emmanuel Okogbenin • Phemba Pezo • Eugene Terry • Graham Thiele • \\ Mike Thresh • Jonathan Wadsworth • Steve Walsh • Stephan Winter • Joe Tohme • Claude Fauquet
}

Received: 7 January 2014 / Accepted: 13 February 2014 / Published online: 3 April 2014

(C) The Author(s) 2014. This article is published with open access at Springerlink.com

\begin{abstract}
The importance of cassava as a food security crop in Africa and the world
Cassava, originally from South America, is the fourth most important source of calories in the developing world after the cereal crops wheat, maize, and rice. Worldwide, it feeds an estimated 700 million people directly or indirectly. Cassava production has increased steadily for the last 50 years, with 242 MT harvested in 2012. The increase is likely to continue as farmers in more than 105 countries come to recognize the crop's advantages. A semi-perennial root crop, cassava can stay in the ground for up to 3 years. This makes it an excellent food security crop: when all other crops have been exhausted, cassava roots can still be harvested. It is naturally drought resistant and resilient to climatic changes, high temperatures, and poor soils, and in addition, cassava responds extremely well to high $\mathrm{CO}_{2}$ concentrations, making it a very important crop for the 21 st century. Africa alone accounts for more than $55 \%$ of the world's production, and cassava is the first food crop in fresh tonnage before maize and plantain in sub-Saharan Africa. Cassava is also an important source of income, especially for women in sub-Saharan Africa (SSA). Furthermore, cassava is the second most important source of starch in the world. Cassava is thus a highly valuable crop for the world today and in the future. It is critical that it should not be compromised by viral diseases.
\end{abstract}

\section{J. Legg}

IITA, Dar es Salam, Tanzania

e-mail: j.legg@cgiar.org

E. A. Somado

AfDB, Tunis, Tunisia

e-mail: e.attiogbevi-somado@afdb.org

E. A. Somado

e-mail: somado@hotmail.com

I. Barker

SFSA, Bale, Switzerland

e-mail: ian.barker@syngenta.com

L. Beach

Washington, DC, USA

e-mail: biot1larry@gmail.com

H. Ceballos $\cdot$ W. Cuellar $\cdot$ C. Hershey $\cdot$ A. Jarvis $\cdot J$. Tohme

CIAT, Cali, Colombia

H. Ceballos

e-mail: h.ceballos@cgiar.org

W. Cuellar

e-mail:w.cuellar@cgiar.org
A. Jarvis
e-mail: a.jarvis@cgiar.org
J. Tohme
e-mail: j.tohme@cgiar.org
C. Hershey
e-mail: c.hershey@cgiar.org
W. Elkhoury
IFAD, Rome, Italy
e-mail: w.elkhoury@ifad.org
D. Gerling
Tel Aviv U., Tel Aviv, Israel
e-mail: dange@tauex.tau.ac.il
J. Helsen
FAO, Juba, South Sudan
e-mail: Jan.Helsen@fao.org
P. Kulakow - L. Kumar
IITA, Ibadan, Nigeria
P. Kulakow
e-mail: P.Kulakow@cgiar.org
L. Kumar
e-mail: L.Kumar@cgiar.org 


\section{Introduction}

Cassava, originally from South America, is the fourth most important source of calories in the developing world after the cereal crops wheat, maize, and rice. Worldwide, it feeds an estimated 700 million people directly or indirectly. Cassava production has increased steadily for the last 50 years, with 242 MT harvested in 2012. The increase is likely to continue as farmers in more than 105 countries come to recognize the crop's advantages. A semiperennial root crop, cassava can stay in the ground for up to 3 years. This makes it an excellent food security crop: when all other crops have been exhausted, cassava roots can still be harvested. It is naturally drought resistant and resilient to climatic changes, high temperatures, and poor soils, and in addition, cassava responds extremely well to high $\mathrm{CO}_{2}$ concentrations, making it a very important crop for the 21 st century. Africa alone accounts for more than $55 \%$ of the world's production, and cassava is the first food crop in fresh tonnage before maize and plantain in sub-Saharan Africa. Cassava is also an important source of income, especially for women in sub-Saharan Africa (SSA). Furthermore, cassava is the second most important source of starch in the world. Cassava is thus a highly valuable crop for the world today and in the future. It is critical that it should not be compromised by viral diseases.

Africa produces more than $50 \%$ of the world's cassava, but the crop faces two formidable disease threats. Cassava mosaic disease (CMD) is present in all cassava-growing countries in Africa and causes losses of at least 45 MT each year (Thresh et al. 1997; Fig. 1). The disease is triggered by the emergence and spread of at least eight species of geminiviruses transmitted by whiteflies (Bemisa tabaci) and disseminated through infected cuttings

\footnotetext{
J. Lorenzen

BMGF, Seattle, USA

e-mail: Jim.Lorenzen@gatesfoundation.org

J. Lynam

Nairobi, Kenya

e-mail: johnklynam@gmail.com

M. McMahon

Washington, DC, USA

e-mail: matthewmcmahon36@gmail.com

G. Maruthi $\cdot$ M. Thresh

NRI, Greenwich, UK

G. Maruthi

e-mail: M.N.Maruthi@greenwich.ac.uk

M. Thresh

e-mail: john.thresh@homecall.co.uk

D. Miano

Nairobi University, Nairobi, Kenya

e-mail: dwatuku@yahoo.com

K. Mtunda

IRA, Dar es Salam, Tanzania

e-mail: kidomtunda@yahoo.com

P. Natwuruhunga

IITA, Lilongwe, Malawi

e-mail: p.ntawuruhunga@cgiar.org

E. Okogbenin

NRCRI, Umudike, Nigeria

e-mail: eokogbenin@yahoo.com

(Fauquet and Fargette 1990; Legg and Fauquet 2004; Patil and Fauquet 2009). It first appeared in 1894 in Tanzania, and several CMD epidemics in Africa have since been reported. The most recent outbreak - and by far the most economically importantbegan in Uganda in the late 1980s (Otim-Nape, et al. 1997; Deng et al. 1997; Zhou et al. 1997). The disease has subsequently invaded most of East and Central Africa (ECA). The pandemic of severe CMD has now affected 12 countries, including Cameroon in West Africa, and continues to spread (Legg et al. 2006). Its effects, however, are most devastating in countries and regions recently affected by the severe CMD pandemic (Legg et al. 2006). In south India and Sri Lanka CMD has caused significant losses; it is absent elsewhere in the world (Patil and Fauquet 2009).

A new virus disease, cassava brown streak disease (CBSD), represents the greatest threat for millions of cassava farmers in ECA. CBSD is caused by two species of ipomoviruses (Winter et al. 2010; Mbanzibwa et al. 2011), also transmitted by whiteflies (Maruthi et al. 2005) and propagated through infected cuttings. First reported in coastal East Africa in (Storey 1936), the disease began to spread in the Great Lakes region of East Africa in 2003 (Alicai et al. 2007). CBSD has a limited effect on the growth and appearance of plants, but can be catastrophic for production as the dry rot that it produces in tuberous roots can render entire crops unusable (Nichols 1950; Hillocks et al. 2001)(Fig. 1).

CMD and CBSD are now the two worst biological constraints to cassava production in Africa-both pandemics are being driven by unusually high populations of the whitefly vector (Legg et al. 2011; Fig. 1). The increasing spread of super-abundant whiteflies raises justifiable fears that CMD and CBSD will spread further on the African continent and

P. Pezo

CRS, Kivu, Democratic Republic of Congo

e-mail: Phemba.phezo@crs.org

P. Pezo

e-mail: phembaphezo@gmail.com

E. Terry

Washington, DC, USA

e-mail: eterry365@gmail.com

G. Thiele

RTB, Lima, Peru

e-mail: g.thiele@cgiar.org

J. Wadsworth

CG Fund Office, Washington, DC, USA

e-mail: jwadsworth@worldbank.org

S. Walsh

CRS, Baltimore, USA

e-mail: stephen.walsh@crs.org

S. Winter

DSMZ, Leibnitz, Germany

e-mail: stephan.winter@jki.bund.de

C. Fauquet $(\bowtie)$

GCP21, CIAT, Cali, Colombia

e-amil: cfauquet@cgiar.org 
worldwide. This would have obvious major and unanticipated consequences for food security, economic development, and social stability in many countries, as much of the world's cassava germplasm is highly susceptible to these viruses. Moreover, global warming is likely to exacerbate the situation because higher temperatures will favor the whitefly vector. This potential additional impact from pest and disease is all the more significant as cassava is one of the very few crops that may otherwise be relatively unscathed by future patterns of climate (Jarvis et al. 2012).

Considerable efforts are being directed at tackling the problem of cassava viruses in Africa. Yet these efforts are not fully coordinated, and the overall scale of mitigation programs is tiny compared with the scale of the threats to the world's cassava crop. With this in mind, the Global Cassava Partnership for the $21^{\text {st }}$ Century - GCP21, a recognized global organization within the cassava community, gathered representatives of 24 research and development (R\&D) organizations and donor agencies at the Rockefeller Foundation Center, in Bellagio, Italy, on 510 May 2013. The workshop established a Global Alliance to Declare a War on Cassava Viruses in Africa, to develop a strategic action plan. The resulting Road Map lays out three primary objectives: to prevent CBSD from reaching Central and West Africa (the largest cassava regions in Africa); to mitigate the effects of these constraints on cassava in parts of Africa already affected; and to prevent the spread of CMD and CBSD to the rest of the world. As described below, the Road Map details a number of immediate, medium- and long-term actions. The overall vision of the Alliance is that this set of actions must be undertaken immediately in a coordinated manner among the international research community, national research organizations and extension services and that these interventions must be sustained long term if they are to be effective and reach their specified goals.

\section{The vision of the Global Alliance is to develop coordinated actions that will limit the spread of CBSD, decrease the impact of CMD and CBSD in Africa, and prevent the global dissemination of both virus diseases.}

\section{Strategic approach}

A "game-changing" vision for the control of cassava viruses in Africa and the world

So far, the international cassava R\&D community has dealt with cassava virus epidemics individually but seldom with coordination among donors, scientists, and developers such as non-governmental organizations
(NGOs). After more than 100 years of losses due to cassava viruses in Africa, the viral situation on cassava has never been worse. Furthermore, the explosion of the CBSD epidemic in East Africa, triggered by the spread of super-abundant whiteflies, has greatly exacerbated virus problems.

Faced with the gravity of this situation, cassava R\&D members know that a greatly strengthened and more effectively coordinated plan is needed to solve these problems. As stated above, the Global Alliance was created to develop a strategic action plan to "declare war on cassava viruses in Africa" in three principal directions. The Alliance's founding document (the Road Map) provides the action framework for the strategy along three different time frames to complete its targets: immediate actions (1-4 years), medium-term actions (5-10 years), and long-term actions (11-20 years) (see Table 1).

The Road Map includes a number of actions along the R\&D continuum and cross-section of cassava stakeholders and actors. Policy makers, scientists, extension services, NGOs, private organizations, and farmer communities have vital roles to play and at a level of collaboration never previously developed. Only through concerted, careful coordination can the proposed actions be managed in space and time to effect substantive and lasting impacts on cassava viruses and, consequently, cassava productivity.

The first action, after publishing the Road Map, will be to engage many more participants at the international, regional, and national levels. It should be possible to implement all activities of the Road Map concurrently. Depending on the type of activities, however, they may last different lengths of time. Actions will certainly continue to be modified in response to changes and outcomes.

The Road Map proposes actions at two geographical levels (Table 2). In Africa, the focus is to halt CBSD's current spread from east to west and tackle cassava viruses and whiteflies in areas already affected by CMD and CBSD pandemics. Globally, addressing the threats of the spread of cassava viruses and super-abundant whiteflies across continents, chiefly South America and Asia, is the priority.

The Road Map represents a fundamental change in the attitude of cassava R\&D professionals - from working a posteriori, to being pro-active. We are well aware of the crop's tremendous future importance to both Africa and the rest of the world, as we strive to feed the planet under constantly changing climatic conditions. Cassava R\&D practitioners are determined to undertake this strategic change in action because not only will it resolve the existing problems of CMD and CBSD in Africa, it will also help us to greatly improve responses to new emerging viral problems that are likely to develop as a consequence of the twin forces of climate change and increased world trade. 


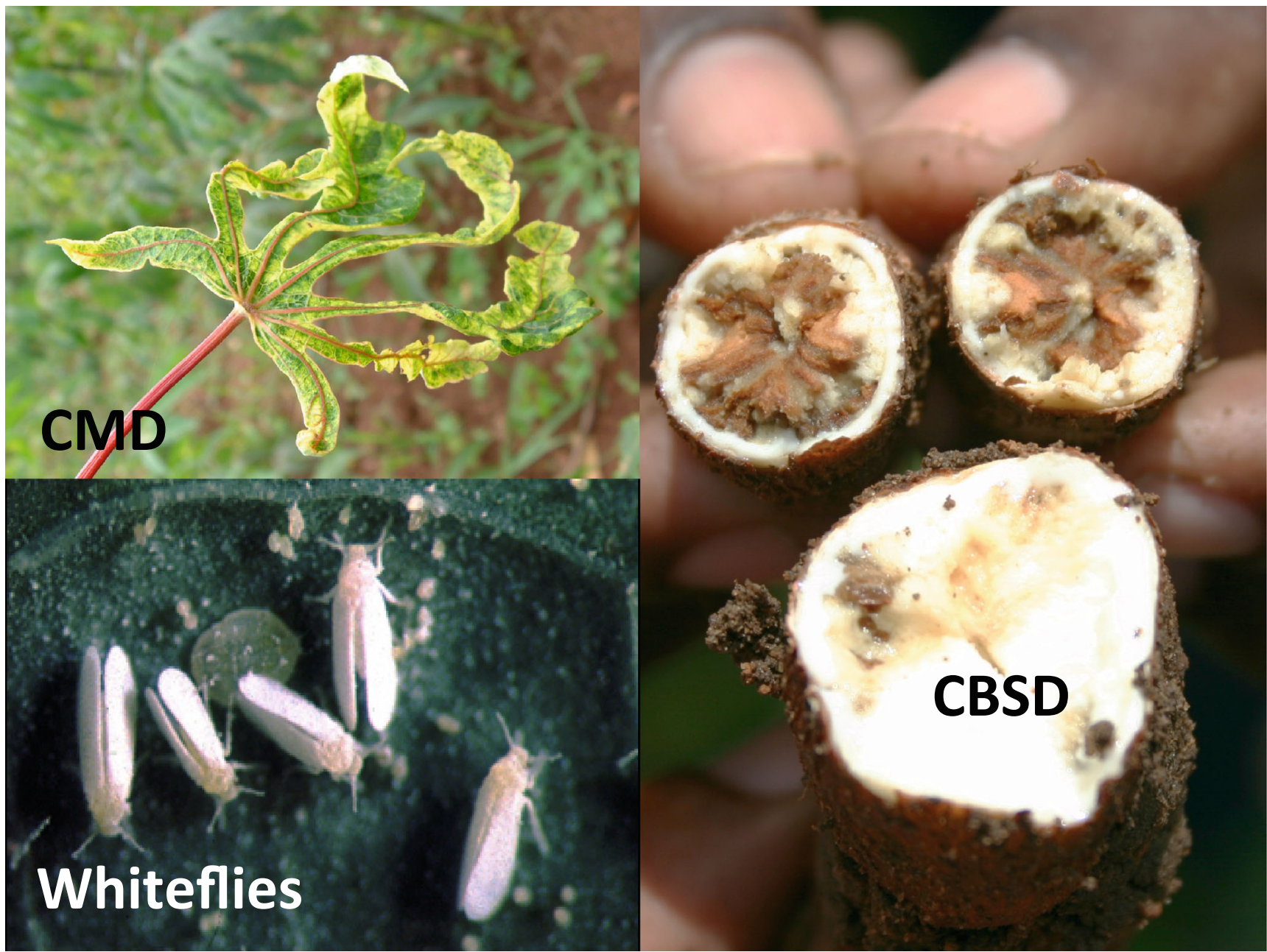

Fig. 1 Symptoms of cassavamosaic disease (CMD) (upper left) and of cassava brown streak disease (CBSD) (right), both diseases being transmitted by the super-abundant populations of whiteflies (Bemisia tabaci) (lower left). (Photographs kindly provided by James Legg)

\section{Action themes}

During the GCP21 workshop in Bellagio, participants reviewed all potential action themes that might be required as components of the strategic Road Map and identified the following action themes as key:

1. Viruses, surveillance, and diagnostics

2. Whiteflies and integrated pest management (IPM)

3. Climate, cassava landscapes, and pest and disease forecasting

4. Breeding

5. Seed systems

6. Capacity development

7. Policy and advocacy

8. Alliance to deliver the strategy.

This section of the Road Map provides a brief introduction to the technical aspects of each action theme - the nature and scope of the problem and plans for how the thematic strategy will tackle the problem. The section then discusses what will be done in this theme to contribute to the aims of the strategy in terms of immediate actions, medium-term actions, and long-term actions.

\section{Viruses, surveillance, and diagnostics}

Urgent action is required to prevent the continued spread of the pandemics of CMD and CBSD. In particular, all possible efforts should be made to ensure that CBSD does not spread from East to West Africa. The first priority is surveillance of areas where CBSD has not yet been reported but nevertheless border regions that are already affected. Meanwhile, ongoing monitoring programs are required in regions affected by the disease and where interventions have been targeted to reduce CBSD occurrence and impact. Surveillance must be linked to a system of reporting and communication (networks) to ensure that infected plants are immediately eradicated when the disease is found in previously unaffected areas. Because new virus diseases can emerge as a result of long distance trade and transport, surveillance for CBSD should be implemented also in cassava-growing regions of Africa not 
directly connected to the regions of current distribution. Surveillance should be undertaken in other cassava-growing parts of the world that have similar climatic conditions to tropical Africa (e.g., the tropics of South America, India, Thailand, Malaysia). Crucial to all activities is a thorough assessment of the human and technical resources available to partners in the field. Accurate virus diagnosis (detection and identification) requires a technical platform of appropriate methods and standardized procedures. These will help to ensure that results are obtained in a timely way and at sufficient resolution and statistical reliability to support decisions on interventions and disease management. Viruses present serious threats to crop cultivation. Newly emerging viruses - or the development of more aggressive strains of existing viruses are difficult to predict. The ultimate goal will be to map all viruses infecting cassava in Africa by establishing a global system of surveillance and monitoring.

\section{Immediate actions}

Virus characterization and surveillance:

- Implement virus characterization studies from countries not yet surveyed to provide comprehensive sequence data for virus diagnostics development.

- Conduct surveillance surveys of viruses causing CMD and CBSD in countries not yet surveyed and repeat surveys in surveyed countries to monitor disease change over time.

- Run focused surveillance surveys in high-risk areas for the spread of CBSD.

- Establish surveillance capabilities in national plant quarantine systems in important cassava-growing countries distant from, but threatened by, CBSD (e.g., Nigeria).

Virus diagnostic methods:

- Develop standardized and robust protocols for detection of all species and strains of viruses causing CBSD and CMD.

- Increase efficiency and reduce cost of existing diagnostics.

- Produce novel diagnostics offering point-of-test functionality.

- Extend diagnostic capabilities to national research and plant protection systems of all countries in Africa greatly threatened by CBSD.

\section{Medium-term actions}

- Establish a database of information on all cassava viruses available at a "click of the button."

- Raise awareness amongst researchers, extensionists, plant protectionists, quarantine officers, farmers, and policymakers of cassava viruses and the threats they pose.

- Strengthen capacity of all cassava stakeholders in understanding, responding to, and managing cassava virus diseases.

\section{Long-term actions}

- Set up virus culture repositories to facilitate easy experimentation on virus resistance and virus-host-vector interactions.

- Establish global virus alert networks to ensure effective communication among countries affected and threatened by cassava virus pandemics and to facilitate rapid responses in case of new outbreaks.

Advances in virus diagnosis will have immediate consequences for other priorities in the Road Map. For example, robust virus diagnosis is a prerequisite for cassava breeders to identify virus resistance or tolerance. It is necessary for seed systems to ensure virus-free propagation of planting material and eventually for improving the system of germplasm exchange.

\section{Whiteflies and IPM: Managing the whitefly vector of cassava viruses in Africa}

Both the cassava mosaic geminiviruses (CMGs) and cassava brown streak viruses (CBSVs) are transmitted by the whitefly vector B. tabaci. Since the 1990s, more than 100 -fold increases in abundance of this insect have been observed on cassava in parts of East Africa. Although not definitively proven, this increase is believed to be the result of genetic changes in whiteflies that have enabled them to become better adapted to cassava and the broader cassava-farming environment. So-called super-abundant whiteflies are so numerous that they can cause direct physical damage to cassava plants that leads to losses of up to $50 \%$. When this is combined with the transmission of CMGs and CBSVs, almost complete crop loss is common. Whiteflies reproduce rapidly and have strong flight capabilities, and so have been driving the virus pandemics of CMD and CBSD throughout ECA, leading to the current direct threats to West Africa.

This component of the war on cassava viruses strategy aims to attack this problem at its core by dramatically reducing the numbers of whiteflies. Doing so will eliminate the problem of physical damage and greatly reduce the spread of existing and future cassava viruses. This will require that the natural balance of cassava plants supporting low numbers of whiteflies - effectively and sustainably managed by natural enemies — be re-established.

\section{Immediate actions}

- Raise awareness in threatened countries of the potential future impacts of whiteflies and cassava viruses and provide training on how to counter these threats.

- Strengthen fundamental knowledge of whitefly invasiveness, adaptability, host preference, and response to climate change to determine the unique characteristics of super- 
abundant whiteflies and develop diagnostic tools to identify them.

- Conduct surveillance in all countries of Central, Southern, and West Africa threatened by the spread of super-abundant whiteflies and identify locations of new outbreaks.

- Develop and implement specific rapid response interventions to control new whitefly outbreaks.

- Evaluate predators and parasitoids to determine the most efficient methods for controlling whiteflies in each of the main agro-ecological environments and study tri-trophic relationships between whiteflies, natural enemies, and cassava host plants. Find plant species that can be used to promote natural control of whiteflies by parasitoids and predators. Introduce and evaluate exotic parasitoids to augment the activity of the local parasitoid fauna.

- Develop "soft" chemistry-based whitefly control strategies for use in high-value cassava systems and determine the impact on natural enemies.

- Set up a publicly shared database on whitefly genotypes on cassava and their distribution within Africa and globally, including parasitoids and predators.

- Work with breeders to develop whitefly-resistant cassava, using conventional and transgenic approaches.

- Develop IPM strategies targeting both non-commercial and commercial cassava growers.

- Provide critical short-term training for researchers and extension staff to counter immediate whitefly threats.

\section{Medium-term actions}

- Apply new knowledge of flora around cassava fields that promote natural enemy activity in developing improved whitefly IPM strategies.

- Rapidly multiply and disseminate exotic parasitoids found to be effective in augmenting the whitefly control provided by local parasitoids.

- Evaluate whitefly-resistant transgenic varieties and determine effects on the natural enemy fauna.

- Strengthen control of super-abundant whiteflies in new outbreak and threatened areas through the deployment and dissemination of whitefly-resistant varieties.

- Disseminate IPM strategies for whitefly control throughout affected countries.

- Strengthen human capacity through a medium-term program of postgraduate studentships and technical training for extension teams.

\section{Long-term actions}

- Model the impacts of climate change on whiteflies and their natural enemies and develop strategies to mitigate any negative impacts on whitefly control.
- Deploy whitefly-resistant transgenic varieties.

- Incorporate novel control tactics into whitefly IPM strategies.

- Extend the dissemination of whitefly IPM strategies for commercial cassava growers to take into account the increasing commercial development of the cassava crop in Africa.

- Document whitefly control impacts.

The implementation of this set of activities should provide effective and sustainable management of whiteflies on cassava in Africa, and will provide an excellent complement to the breeding and virus control activities proposed in other sections of the Road Map.

\section{Climate, cassava landscape, and pest and disease predictions}

Cassava is a hardy crop that can grow in many hot and dry regions of the globe. Not only is cassava highly resistant to many of the harshest climates typical of today's tropics, it also will continue to thrive under projected 2030 climates, especially when compared to other important staples. This makes cassava an essential resource for smallholder farmers in marginal areas. It provides options as a substitution crop for other staples more sensitive to climate (e.g., potato, maize), or could play a role in on-farm diversification strategies to better manage climate risk. Climate change also presents options in the sub-tropics where cold temperatures limit cassava production. As temperatures rise, these areas may experience increases in potential yield. The models used for these studies are agro-ecological zoning-based approaches using the EcoCrop model. For a true understanding of crop-climate response of cassava, a mechanistic crop model is needed.

Little is known about the impact that climate change might have on pests and diseases. Already a major constraint, these could be the primary factor that suppresses cassava farming in the tropics and sub-tropics. Numerous studies have shown that the distribution of insect pests has been driven by climatic conditions. Temperature affects life-cycles of insects, and precipitation and relative humidity also affect prevalence of pests. Likewise, climate in some cases affects the distribution of viruses directly, although little evidence is available that climate (and climate change) is restricting (or enabling) the spread of cassava viruses in SSA. But substantial evidence does exist on the effects of temperature on virus concentration and consequent symptom severity. As such, climate change is certain to have significant effects on cassava virus epidemiology. Niche-based approaches have been used for whiteflies to examine the possible effects of climate change, and show changes in their geographic distribution patterns. However, these approaches are rudimentary and require further work for the results to be robust and actionable. Other approaches are 
needed, such as more mechanistic models of insect pests, integrating host-plant resistance, and impacts on other physiological processes.

If the relationship between climate, crop, and pests and diseases is better understood, this will permit predictive modeling of pest and disease spread, and provide the ability to test potential technological or management interventions and their efficacy in dealing with the constraints being felt by farmers. Modeling activities could thus be a key element of future mitigation strategies for cassava viruses and their insect vectors.

\section{Immediate actions}

- Assemble a global database of surveillance information for cassava viruses and their vectors.

- Develop an online interface that maps pest and disease presence and spread based on surveillance reports of viruses and their vectors. The interface will initially be populated with data from the global database, but this will be regularly updated as new surveillance data become available.

\section{Medium-term actions}

- Develop a cassava mechanistic crop model that explicitly understands the relationship between crop and climate, and that can predict yields for a range of varieties across a range of climate conditions. This can then be used to inform management and policy decisions in cassava $\mathrm{R} \& \mathrm{D}$.

- Incorporate the results of the model into the mapping interface for decision makers to consult.

\section{Long-term actions}

- Use a range of methods to better understand the relationship between pests and diseases and the climatic conditions under which they develop. Large datasets based on field measurement of pest/disease prevalence and impact could be used to generate robust statistical relationships that can then be used for prediction, or provide crucial input to couple pest and disease presence, prevalence, and impact through the cassava crop model.

- Incorporate the results into the cassava online interface.

All these actions will provide analytical tools that may also be used to model the development of new pests and diseases of cassava which specialists predict will occur as temperatures continue to increase in the decades to come.

\section{Breeding}

Genetic improvement and breeding for resistance to virus diseases of cassava started in the 1930s in East Africa and Madagascar. Initial evaluation of landraces led to the conclusion that there was no adequate resistance available in the cultivated species, and motivated the search for resistance in species of wild cassava. Among several species tested, M. glaziovii was identified as a source of resistance, and crossed into local clones in Madagascar and in the Amani program of Tanganyika (present day Tanzania). From this initial breeding effort, based on a polygenic source of resistance, the first deployed CMD-resistant varieties were developed by breeding programs in Africa with significant success. Through the 1990s, these original sources of resistance from the Amani program continued to be the main focus of CMD resistance breeding.

The CMD epidemic in East Africa in the 1990s prompted strong breeding initiatives that led to the discovery and deployment of stronger sources of resistance. Single-gene resistance from cmd2 has been applied successfully in combating the disease in Nigeria and elsewhere. More recently, another resistance gene, $\mathrm{cmd} 3$, has been hypothesized to explain higher levels of resistance to CMD in some progenies.

While extensive deployment of CMD-resistant varieties has been pursued throughout the cassava belt of Africa, it is based on a limited number of varieties. Other key challenges affecting breeding capacity include the limited understanding of mechanisms of resistance, as well the limited knowledge of resistance genes for CMD (and even less for CBSV; none for whiteflies). Focused genetic improvement and breeding strategies based on efficient molecular tools and simplified protocols are central to the war on cassava viruses.

Although high levels of genetic improvement have been achieved for CMD, the ravaging scourge of CBSD in ECA threatens to erode the genetic gains made in the fight against CMD. Breeding for CBSD resistance is still relatively recent compared to that for CMD. CBSD is an old disease, but became a major threat only in the last decade. Only moderate tolerance exists in the cultivated gene pool.

\section{Immediate actions}

- Release multiple farmer-preferred varieties with CBSD and CMD tolerance/resistance, based on efficient breeding programs, delivery mechanisms, and community-based propagation systems.

- Establish nuclear stocks of ISO-accredited (International Organization for Standardization-accredited) material for all released resistant varieties in target regions.

- Screen a much broader base of germplasm for resistance.

- Confirm existing reported resistance through rigorous testing protocols and refinement of screening methods for resistance.

- Improve knowledge of interactions of virus isolates with resistance mechanisms. 
- Test genotype-environment interactions for symptom expression/resistance to $\mathrm{CMD} / \mathrm{CBSD} /$ whiteflies and their effect on yield and quality.

- Exchange germplasm from the genebanks of CIAT and IITA, using virus indexing and deep sequencing to confirm virus-free status.

- Produce and test transgenic, farmer-preferred varieties resistant to CMD and CBSD.

- Develop known whitefly resistance in breeding programs.

- Determine genes associated with identified resistance.

- Understand mechanisms and durability of resistance genes, and their molecular interaction with different virus isolates.

- Use genome-wide selection and sequencing of progenies to increase the speed of resistance breeding for cassava viruses and whiteflies.

- Establish multidisciplinary researcher networks for the development of CMD, CBSD, and whitefly resistance.

\section{Medium-term actions}

- Develop preemptive breeding for CBSD and whitefly resistance in West Africa, using centralized screening facilities based on regional and national action plans.

- Develop preemptive breeding against CMD, CBSD, and whiteflies in the Americas and in Asia, in anticipation of their possible future introduction. It is almost certain that the vast majority of landraces and improved varieties in both the Americas and in Asia are fully susceptible to both diseases and to whiteflies. The exceptions are some whitefly-resistant cultivars in the Americas and India, where there has been long-term breeding for resistance to CMD viruses.

- Deploy transgenic varieties (resistant to both viruses and whiteflies) developed from farmer-preferred cultivars, as a complement to conventional breeding in threatened areas.

- Identify new sources of virus and whitefly resistance in wild and cultivated germplasm (with priority on cultivated cassava).

\section{Long-term actions}

- Deploy varieties resulting from new strategies (e.g., genomic selection) to enhance fast delivery of the breeding process, with resistance to $\mathrm{CMD} / \mathrm{CBSD} /$ whiteflies and also farmerpreferred agronomic, cooking, and organoleptic traits.

- Use fine mapping to transfer identified resistance genes to farmer-preferred cultivars.

- Understand genetic effects on resistance mechanisms at the molecular level through comparative genomics.
- Understand and use resistance via gene-editing techniques.

- Discover allelic variance in genebanks through sequencing, and assess dosage effects in polyploidy.

\section{Seed systems}

Cassava's slow multiplication rate, clonal propagation method, and bulkiness of planting material have significant implications on improving its seed systems, including the breeding strategy, varietal release policy, and extension approach for new varieties (multilocation participatory varietal selection trials). It also has implications for the introduction of an effective incentive structure for non-project-driven private sector cassava seed system investments (virus-indexed tissue culture, "clean" and/or low virus incidence foundation seed, decentralized community-based stem and cutting producers).

There has been no private sector investment in cassava breeding in Africa and only limited investment by the public sector. As such, cassava breeding has focused mainly on developing widely adapted disease-resistant clones. In general, there have been limited efforts to integrate breeding with farmer-managed cassava systems to speed up genetic variability in seed systems and increase the potential for evaluation under diverse conditions. There is significant scope for improved integration and synergy within and between national programs and host-country farmers.

The development of a formal cassava varietal release policy is in its infancy in most countries in SSA, and has allowed stem producers and farmers to work outside the system. For example, several cassava varieties are officially released years after the same varieties have become widely accepted and grown by farmers. Although an open quarantine policy was used successfully to speed up the movement of CMD-resistant varieties throughout the Great Lakes region of ECA from the mid 1990s, the advent of CBSD in this same region consequently led to the end of open quarantine, as CBSD infection may often be symptomless. Currently, it can take at least four years for a released variety to be introduced to a new country, as it needs to be virus-indexed and put into tissue culture before being transported, bulked on station in the recipient country, then evaluated for a minimum of two seasons of trials.

Little is known about the market demand and willingness of farmers to pay for virus-indexed tissue culture plantlets and clean or low virus foundation seed stock. Seed investment models from private sector potato seed companies and ongoing degeneration research should provide useful reference points in making recommendations on the use of virus-indexed tissue culture material or on the acceptable level of disease incidence for foundation and decentralized community-based seed producers.

Promoting farmer access to new disease-tolerant cassava varieties or to existing disease-free cassava varieties requires a decentralized production approach. This approach is 
characterized by many small producers, minimal but effective oversight to ensure adherence to a contextually appropriate farmer-centric quality declared seed standard, and coordination among a myriad of actors spanning host government, research, humanitarian relief organizations, community-based organizations, and farming communities.

\section{Immediate actions}

- In CBSD epidemic and threatened countries, identify, select, and screen farmer-preferred varieties to CBSD through establishing multilocation disease testing sites where farmer-preferred clones are evaluated for performance against $\mathrm{CBSD}$ and $\mathrm{CMD}$.

- In CBSD epidemic and endemic countries, promote contextually specific farmer-centric stem quality standards for cassava stem growers.

- Reevaluate varietal release and open quarantine policies, notably for endemic CBSD countries.

- In CBSD endemic areas within countries, promote farmer and community-based phytosanitation combined with the sourcing of planting material from isolated and diseasefree bulking sites.

- In CBSD epidemic, endemic, and threatened countries, conduct communication campaigns targeting cassava virus diseases and cassava seed systems aimed at policymakers, humanitarian partners, and farmers.

- Establish national and regional platforms that will allow researchers, policymakers, and civil society organizations to share information and coordinate activities relative to cassava seed systems and virus disease in Africa.

\section{Medium-term actions}

- In disease-endemic zones, build the capacity of commercially independent cassava stem producers (using where possible a combination of tissue culture virus-indexed material and low/no disease foundation material).

- Develop farmer-centric quality stem standards based on degeneration evidence and farmers' willingness to pay for disease-free/low disease planting material.

- Strengthen the capacity of small- and medium-scale enterprises in community-based seed processing with the target of putting pressure on cassava producers to promote disease-tolerant planting material and adhere to quality stem standards (demand pull).

\section{Long-term actions}

- Establish a multinational farmer-owned cooperative of decentralized stem and mini-stem producers capable of exercising lobbying authority and influence on both research and national governments.

\section{Capacity development}

A comprehensive capacity-development program is required to decrease the impact of cassava viruses in Africa and to slow down their spread to other parts of Africa and beyond. Such a program should involve the strengthening of human resources, infrastructure, laboratory facilities, screen houses, and improvements in procurement systems. Research capacity in SSA has increased greatly over recent decades. But progress has not kept pace with the demands imposed by everexpanding pest and disease problems, and efforts at capacity development have been very uneven. Some countries have benefited greatly from human and physical capacity strengthening, with large increases in the numbers of postgraduate-trained researchers and newly constructed laboratories. Others have seen much less progress. A key focus for the contribution of capacity development to the war on cassava viruses will be on support for countries that currently have weaker than average capacity. Most importantly, the countries of Central Africa, which are on the leading edge of the westward spread of CBSD, will require particular support.

At the outset, needs assessments will be required to identify gaps across countries in Africa and potential intervention activities. These assessments should consider the cassava-growing regions of SSA as a whole, to ensure that no gaps are left that may compromise future achievements. Needs assessment exercises will help to provide an inventory of who is available with which specialization and what is available in terms of infrastructure and facilities. Although there are specific needs for training and capacity building in each discipline listed in each topic, it is important to envisage building capacity as a whole for this strategic framework, encompassing all disciplines and requirements. Ultimately, a plan of action for capacity building based on identified gaps should be developed, focusing on short-, medium-, and longterm training; lab facilities; and other important infrastructures. The infrastructural development should focus on sustainable mechanisms that can last beyond project lifespans.

\section{Immediate actions}

- Assess needs for short-, medium-, and long-term training in target countries.

- Produce an inventory of facilities that can contribute to the "war on cassava viruses" Road Map. 
- Raise awareness of policymakers, administrators, and regulators in target countries.

- Raise awareness and provide training for extension service officers and farmers in target countries, making use of the full range of communications media, including new technologies.

- Raise awareness within the private sector in target countries about cassava viruses, the importance of using and producing clean planting material, and the risks of moving germplasm without regulatory support.

- Provide short-term technical training for technicians and scientists involved in surveillance of CMD/CBSD and whiteflies in target countries.

- Upgrade existing facilities to enable them to fully support the different types of actions identified under the various action themes of the Road Map.

\section{Medium-term actions}

- Build new facilities to support the implementation of the different types of actions proposed within the Road Map: laboratories, multiplication and propagation centers, quarantines, facilities, and others.

- Educate the next generation of students, technicians, and scientists to participate in the war on cassava viruses in the full range of action themes envisaged within the Road Map through postgraduate training in existing schools and universities.

- Develop and run short-term courses to continuously train the necessary personnel to perform all the tasks envisaged within the Road Map.

\section{Long-term actions}

- Create and organize cassava courses comprising all aspects of virology, entomology, breeding, IPM, development, seed quality control, commercialization of quality seeds, economics, and impact assessment.

\section{Policy and advocacy}

While there are many scientific, technical, institutional, and socioeconomic challenges facing the international community in their endeavor to win the declared war on cassava viruses, the policy-related challenge is often neglected and its potential impact underestimated. There remains insufficient awareness and recognition at the policy-making level of the risks and the urgent action needed to prevent or reduce the impact of the diseases. Even when awareness is generated, the difficulty remains in creating sufficient conviction and motivation to translate this awareness into action through sufficient and timely mobilization of financial and human resources. The challenge is greater with policymakers (nationally and globally, including the donor community) when dealing with aspects of prevention and risk mitigation rather than a response to an already existing problem with measurable obvious damage.

Other national policy-related challenges that should be managed to achieve the objectives of the Road Map include mechanisms to enhance coordination and information exchange across sectors, especially among research, extension, and plant protection. This applies as well to other nonagriculture sectors and institutions such as education, trade, transport, and environment. Similar challenges exist at the regional and international levels to overcome the insufficient coordination and information exchange across countries in a region and between continents to optimize containment and effectively mobilize resources when there is a threat.

What is the policy target audience?

- National or local policy and decision-makers dealing with agricultural research, extension, and plant protection

- National policy and decision-makers dealing with issues affecting hunger, food aid, health/nutrition, displaced people, conflict, post-conflict recovery, and social/productive safety nets

- Constituency of local communities affected or potentially affected who could be mobilized as groups to establish and implement community-based regulations and by-laws

- Regional economic and research organizations and networks involved in economic and agricultural policy setting, harmonization procedures, and regulatory issues (ECOWAS (Economic Community Of West African States), NEPAD (New Partnership for Africa's Development), ASARECA (Association for Strengthening Agricultural Research in Eastern and Central Africa), CORAF/WECARD (West and Central African Council for Agricultural Research and Development), etc.)

- UN and other intergovernmental agencies and the donor community involved in such areas as agricultural development, poverty alleviation, food and social security, disaster risk reduction, and environment

- International and national NGOs working in such fields as hunger and rural poverty alleviation, livelihoods, mass migration, welfare, and justice.

What is the strategy?

To mobilize policymakers, the objectives of the declared war against cassava viruses should be framed within the context of a developmental objective, not a scientific or research framework. The objective should reflect the importance of cassava for food security and in the livelihoods of 
smallholder producers both in Africa and globally. It should also reflect the need for national governments and the international society to ensure that sufficient resilience is provided to the farmers to deal with the present viral epidemics as well as in anticipation of the emergence of future new pandemic diseases.

The strategy for policy support should consider:

- Alignment with national development plans and strategies, including CAADP (Comprehensive African Agricultural Development Plan)

- Alignment with national institutional set-up and mandates in relation to the countrys' capacity to respond to such pandemics

- Alignment with national policy and regulatory frameworks

- Countrys' obligations to regional and global agreements and conventions.

\section{Immediate actions}

- Prepare theory of change for advocacy and anticipated policy change with targets.

- Prepare a counterfactual theory of change (i.e., a Nick Stern approach): what are social costs and consequences of doing nothing, doing too little, or doing it too late?

- Systematically gather evidence of scale of impacts and potential benefits of containment and recovery to guide advocacy (ex ante impact assessment).

- Prepare and establish a bank of relevant advocacy and knowledge management material to be used when needed (an image bank and testimonies of farmers whose livelihoods have been undermined by CBSD and CMD, locate worst-affected sites, find ways of getting high-profile people to visit them, make videos, get passionate journalists fired up to the hidden threat that is being ignored, etc.).

- Identify key stakeholders (farmers associations, NGOs, traders, poor consumers, women's groups) who can be mobilized to put pressure on policymakers.

- Get one or more high-profile individuals (such as the expresident of Nigeria who is an IITA goodwill ambassador) to champion the cause.

- Develop a communications strategy with key messages for immediate action, and with phases for medium- and long-term engagement to build and sustain interest.

\section{Medium- and long-term actions}

- Make use of bank of advocacy and knowledge management material for communications.
- Use ex-post impact assessments of immediate actions and refined ex-ante assessments of planned future actions to strengthen case for sustained and expanded interventions.

- Identify stakeholder beneficiaries of immediate actions to lead advocacy efforts for sustained efforts to tackle cassava virus pandemics.

\section{Alliance to deliver the strategy}

Here we outline the network of partners that will be required if we are to realize the overall goal of overcoming the threat of virus diseases of cassava at the global level.

What is the problem?

Currently there is no overall coordination amongst the many stakeholders who need to come together to address the complex problem of reducing and eventually eliminating cassava viruses in Africa in order to effect large improvements in livelihoods for producers and consumers of the crop. This lack of coordination leads to overlaps and duplication in research efforts, misallocation of resources, and gaps that are not addressed by any stakeholder. There is no overall framework, no coalition of the willing to mobilize the resources and skills required to draw attention to the risks and address the problem.

\section{What is its scope?}

All of the partners and stakeholders in research on genetic improvement of cassava and the management of viruses and whiteflies, extension actors, plant protection agencies, and government policymakers and funders have to be involved to ensure success of the war on cassava viruses.

What is the overall strategy to tackle it?

We need to create a broad-based coalition of the willing that includes the key partners and stakeholders to agree a joint vision to move ahead on fully exploiting this Road Map. We need to agree overall responsibilities, seek targeted funding, implement the Road Map, and continuously learn and improve amongst the partners to grow the Global Alliance (Fig. 2). This will require a user-friendly monitoring system to learn, track progress, and show value for money to funders. The Global Alliance can be hosted within the GCP21 as a broad-based partnership platform supported by and linked with the CGIAR 


\section{War on Cassava Viruses Road Map}

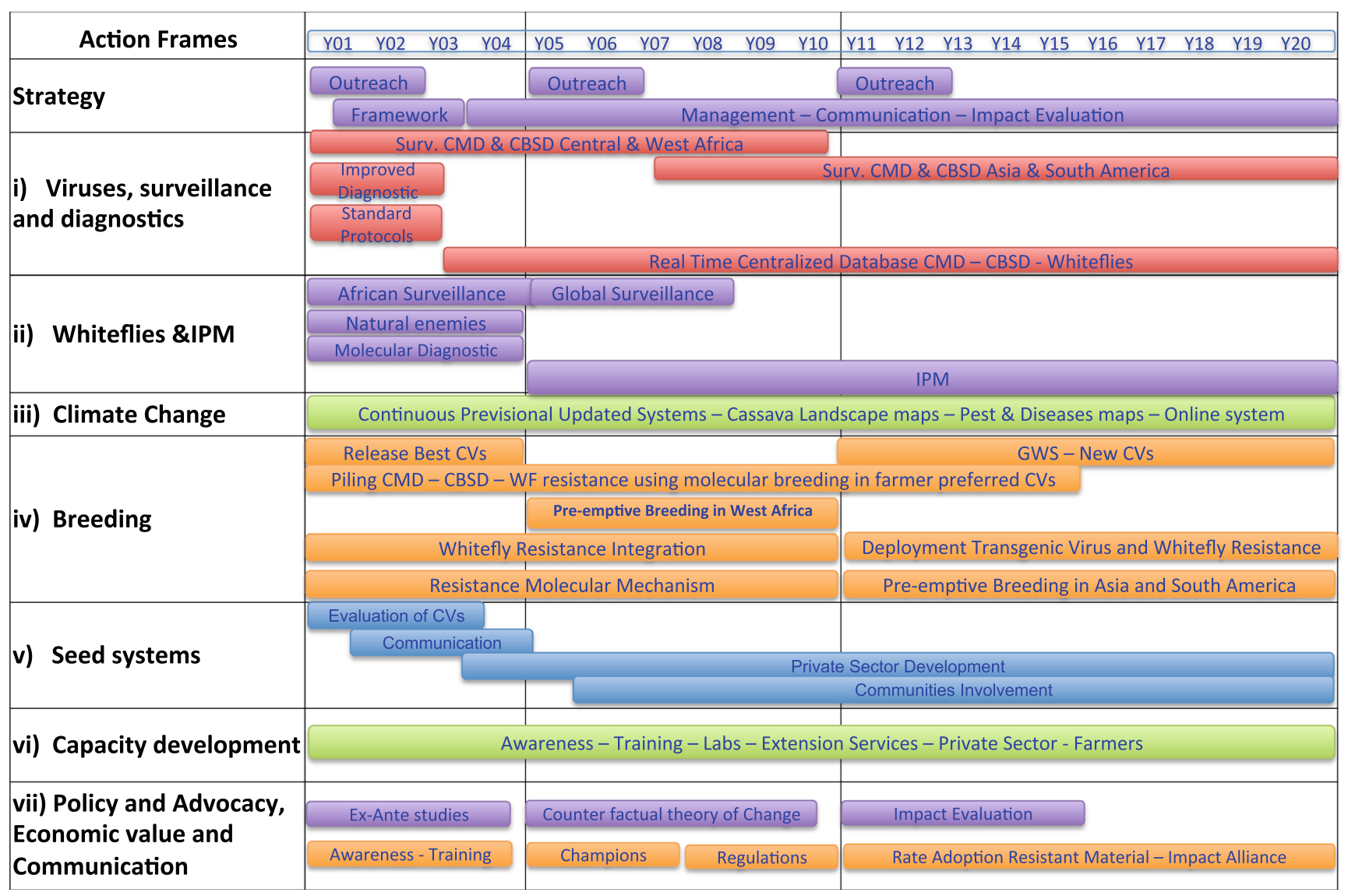

Fig. 2 Framework of the road map of the Global Alliance to Declare a War on Cassava Viruses

Research Program on Roots, Tubers and Bananas (RTB), which mobilizes research for development through its flagships.

\section{Immediate actions}

- Agree on the partnership framework for the coalition what it is called, how membership is defined. What is the relationship with the GCP21 and RTB and the rest of the community?

- Finalize the Road Map linked to the partnership framework.

- Prepare a compelling business case showing the costs of not moving ahead with our proposal.

- Prepare a theory of change (impact pathway) for the coalition showing the phased outcomes expected and the partners to be engaged (including the role of advocacy in creating an enabling policy environment).
- Develop an action framework plan with all partners.

- Develop options for partnerships in the medium and longer term linked to landscape analysis and foresight studies.

\section{Medium- and long-term actions}

- Conduct regular meetings at the regional and global levels to review projects, progress, and problems.

- Monitor progress in a coordinated manner, and provide feedback to all partners.

\section{Conclusion}

For the first time, the international cassava community has agreed to create a Global Alliance to "declare war on cassava viruses in Africa." Owing to global climatic changes and 
increased international trade, extremely dangerous cassava diseases may possibly invade the whole African continent and potentially beyond. The two most important cassava virus diseases, CMD and CBSD, have been present in Africa for nearly a century or more. They are still the most important biological constraints for cassava productivity in Africa. This situation has recently been made dramatically worse by the emergence and spread of super-abundant populations of the whitefly vector of both viruses. These insects have already driven a severe CMD pandemic through a dozen countries in ECA; they are in the process of doing the same for a CBSD pandemic. Most worryingly, they now threaten to carry new epidemics of the two diseases into the major cassava-growing areas of West Africa, which would lead to unprecedented losses. All the cassava cultivars grown in the rest of the world are susceptible to these diseases. If super-abundant whiteflies were to spread to Latin America or Asia, CMD and CBSD would spread very rapidly and cause economic and humanitarian disasters. The international cassava community is conscious of these real threats, and has decided to create a Global Alliance to fight these scourges. The Alliance's war on cassava viruses has the twin aims of slowing down the spread of CMD and CBSD in Africa and limiting their possible invasion of the other cassava-growing regions of the world. The Global Alliance has developed a Road Map of key thematic actions to be undertaken in three time frames: immediate, medium-term, and long-term. If embraced by all cassava stakeholders and actors, the Road Map will bring about a different mode of working for the international community. If successful, this new mode of collaboration will allow cassava to fulfill its very great potential as a climate-stable super crop of the 21 st century, capable of feeding billions of people by 2050 .

Acknowledgments The authors wish to thank the program Roots, Tubers and Bananas (RTB) for covering the cost of editing and publishing this article.

Open Access This article is distributed under the terms of the Creative Commons Attribution License which permits any use, distribution, and reproduction in any medium, provided the original author(s) and the source are credited.

\section{References}

Alicai, T., Omongo, C. A., Maruthi, M. N., Hillocks, R. J., Baguma, Y., Kawuki, R., Bua, A., Otim-Nape, G. W., \& Colvin, J. (2007). Reemergence of cassava brown streak disease in Uganda. Plant Disease, 91, 24-29.

Deng, D., Otim-Nape, G. W., Sangare, A., Ogwal, S., Beachy, R. N., \& Fauquet, C. M. (1997). Presence of a new virus closely associated with cassava mosaic outbreak in Uganda. African Journal of Root and Tuber Crops, 2, 23-28.
Fauquet, C., \& Fargette, D. (1990). African cassava mosaic virus: etiology, epidemiology and control. Plant Disease, 74, 404411.

Hillocks, R. J., Raya, M., Mtunda, K., \& Kiozia, H. (2001). Effects of brown streak virus disease on yield and quality of cassava in Tanzania. Journal of Phytopathology, 149, 1-6.

Jarvis, A., Ramirez-Villegas, J., Herrera Campo, B. V., \& NavarroRacines, C. (2012). Is Cassava the Answer to African Climate Change Adaptation? Tropical Plant Biolology, 5, 9-29. doi:10. 1007/s12042-012-9096-7.

Legg, J. P., Jeremiah, S. C., Obiero, H. M., Maruthi, M. N., Ndyetabula, I., Okao-Okuja, G., Bouwmeester, H., Bigirimana, S., Tata-Hangy, W., Gashaka, G., Mkamilo, G., Alicai, T., \& Lava Kumar, P. (2011). Comparing the regional epidemiology of the cassava mosaic and cassava brown streak pandemics in Africa. Virus Research, 159, $161-170$.

Legg, J. P., Owor, B., Sseruwagi, P., \& Ndunguru, J. (2006). Cassava mosaic virus disease in East and Central Africa: Epidemiology and management of a regional pandemic. Advances in Virus Research, 67, 355-418.

Legg, J. P., \& Fauquet, C. M. (2004). Cassava mosaic geminiviruses in Africa. Plant Molecular Biology, 56(4), 585-599.

Maruthi, M. N., Hillocks, R. J., Mtunda, K., Raya, M. D., Muhanna, M., Kiozia, H., Rekha, A. R., Colvin, J., \& Thresh, J. M. (2005). Transmission of Cassava brown streak virus by Bemisia tabaci (Gennadius). Journal of Phytopathology, 153, 307-312.

Mbanzibwa, D. R., Tian, Y. P., Tugume, A. K., Patil, B. L., Yadav, J. S., Bagewadi, B., Abarshi, M. M., Alicai, T., Changadeya, W., Mkumbira, J., Muli, M. B., Mukasa, S. B., Tairo, F., Baguma, Y., Kyamanywa, S., Kullaya, A., Maruthi, M. N., Fauquet, C. M., \& Valkonen, J. P. T. (2011). Evolution of cassava brown streak disease-associated viruses. Journal of General Virology, 92, 974-987.

Nichols, R. F. J. (1950). The brown streak disease of cassava: distribution, climatic effects and diagnostic symptoms. East African Agricultural Journal, 15, 154-160.

Otim-Nape, G. W., Bua, A., Thresh, J. M., Baguma, Y., Ogwal, S., Semakula, G. N., Acola, G., Byabakama, B., \& Martin, A. (1997). Cassava mosaic virus disease in Uganda: The current pandemic and approaches to control. Chatham, Kent: Natural Resources Institute.

Patil, B. L., \& Fauquet, C. M. (2009). Cassava mosaic geminiviruses: actual knowledge and perspectives. Molecular Plant Pathology, 10, 685-701. doi:10.1111/J.1364-3703.2009. 00559.X.

Storey, H. H. (1936). Virus diseases on East African plants. VI. A progress report on the studies of the diseases of cassava. East African Agricultural Journal, 2, 34-39.

Thresh, J. M., Otim-Nape, G. W., Legg, J. P., \& Fargette, D. (1997). African cassava mosaic virus disease: The magnitude of the problem. African Journal of Root and Tuber Crops, 2, 13-19.

Winter, S., Koerbler, M., Stein, B., Pietruszka, A., Paape, M., \& Butgereitt, A. (2010). The analysis of cassava brown streak viruses reveals the presence of a distinct virus species causing cassava brown streak disease in East Africa. Journal of General Virology, 91, 1365-1372.

Zhou, X., Liu, Y., Calvert, L., Munoz, C., Otim-Nape, G. W., Robinson, D. J., \& Harrison, B. D. (1997). Evidence that DNA-A of a geminivirus associated with severe cassava mosaic disease in Uganda has arisen by interspecific recombination. Journal of General Virology, 78, 2101-2111. 
Table 1 Major activities by theme of the Road Map for the War on Cassava Viruses in Africa

\section{IMMEDIATE ACTIONS (1-4 YEARS)}

\section{VIRUSES}

a. Virus characterization studies from unsurveyed countries to provide sequence data for diagnostic tests.

b. Run surveys of viruses causing CMD and CBSD in unsurveyed countries and repeat surveys in surveyed countries to monitor disease change over time.

c. Run focused surveillance surveys in high-risk areas for the spread of CBSD.

d. Establish surveillance capabilities in national plant quarantine systems in important cassava-growing countries threatened by CBSD: Optimization, simplification and harmonization of virus diagnostic methods.

e. Develop standardized and robust protocols detecting all species and strains of viruses for CBSD and CMD.

f. Increase efficiency and reduce cost of existing diagnostics.

g. Produce novel diagnostics offering point of test functionality.

h. Extend diagnostic capabilities to national research and plant protection systems of all countries in Africa greatly threatened by CBSD.

\section{WHITEFLIES}

Raise awareness in threatened countries of the potential future impacts of whiteflies and cassava viruses and provide training on how to counter these threats.

a. Strengthen fundamental knowledge of whitefly and the unique characteristics of super-abundant whiteflies and develop diagnostic tools to identify them.

b. Conduct surveillance in all African countries threatened by super-abundant whitefly.

c. Develop and implement specific rapid response interventions to control new whitefly outbreaks.

d. Evaluate predators and parasitoids to control whiteflies. Find plant species that can be used to promote natural control of whiteflies by parasitoids and predators. Introduce and evaluate exotic parasitoids to augment the activity of the local parasitoid fauna.

e. Develop soft chemistry insecticides for whitefly control and determine the impact on natural enemies.

f. Set up a public database for whitefly genotypes on cassava: distribution, parasitoids and predators.

g. Work with breeders to develop conventional and transgenic whitefly resistant cassava.

h. Develop IPM strategies targeting both non-commercial and commercial cassava growers.

\section{CLIMATE CHANGE}

a. Assemble a global database of surveillance information for cassava viruses and their vectors.

b. Develop an online interface, mapping pest and disease presence and previsions.

\section{BREEDING}

a. Promote the release of varieties with CBSD and CMD tolerance/resistance.

b. Establish nuclear stocks of ISO-accredited material for all the released resistant varieties.

c. Screen a much broader base of germplasm for resistance.

d. Confirm existing reported resistance through rigorous refined testing protocols.

e. Improve knowledge of interactions of virus isolates with resistance mechanisms.

f. Test gene - environmental (GxE) interactions for symptom expression/resistance to CMD/CBSD/whiteflies.

g. Exchange of virus indexed and deep sequenced genebank material between CIAT and IITA.

h. Produce and test transgenic varieties resistant to CMD and CBSD in farmer-preferred cultivars.

i. Use known Bemisia tabaci resistance in breeding programs.

j. Determine the genetic basis of identified resistance and identification of resistance gene(s).

$\mathrm{k}$. Understand molecular resistance mechanisms and durability with different virus isolates.

1. Develop modern breeding technologies including genome wide selection.

$\mathrm{m}$. Strengthen networks of breeders in multidisciplinary research teams on CMD, CBSD and whitefly resistance.

\section{SEED SYSTEMS}

a. In CBSD epidemic and threatened countries, identify, select, and screen farmer-preferred varieties to CMD and CBSD resistance through multi-location disease testing sites.

b. In CBSD epidemic and endemic countries, promote farmer-centric stem quality standards for stem growers.

c. Re-evaluate varietal release and open quarantine policies, notably for endemic CBSD countries.

d. In CBSD endemic areas within countries, promote farmer and community-based phytosanitation combined with the sourcing of planting material from isolated and disease-free bulking sites.

e. In CBSD epidemic, endemic, and threatened countries, conduct communication campaigns targeting cassava viral diseases and the cassava seed system, aimed at policy makers, humanitarian partners and farmers.

f. Establish national and regional platforms for cassava research, policy makers, and civil society organizations to share information and coordinate activities relating to cassava seed systems and viral disease in Africa.

\section{CAPACITY BUILDING}

a. Assess needs in training for short, medium and long term in target countries.

b. Compile an inventory of facilities capable of participating in the actions of the Road Map. 
Table 1 (continued)

c. Raise awareness of policy makers, administrators and regulators in target countries.

d. Raise awareness and provide training for extension service officers and farmers in target countries, making use of the full range of communications media, including new technologies.

e. Raise awareness within the private sector in target countries about cassava viruses, the importance of using and producing clean planting material, and the risks of moving germplasm without regulatory support.

f. Provide short-term technical training of technicians and scientists involved in surveillance of CMD/CBSD and whiteflies in target countries.

g. Upgrade existing facilities to participate in the different actions listed in the Road Map.

POLICY-MAKERS, ADVOCACY

a. Prepare a theory of change for advocacy and anticipated policy change with targets.

b. Prepare a counterfactual theory of change - the real crisis scenario.

c. Produce an ex-ante impact assessment indicating the potential benefits of containment and recovery to guide advocacy.

d. Establish a database of relevant advocacy and knowledge management material: image and video bank; testimonies of farmers; inventory and visits of high profile people and journalists to the worst affected sites.

e. Identify key stakeholders - farmers associations, NGOs, traders, consumers, women's groups - to mobilize policy makers.

f. Identify champions to mobilize public and policy makers.

g. Develop a communication strategy with key messages for immediate action with phases for medium and long term to build and sustain interest.

STRATEGY

a. Agree on the partnership framework for the coalition, including its title and how membership is defined. Define the relationship between GCP21, RTB and the rest of the cassava R4D community?

b. Finalize the Road Map linked to the partnership framework.

c. Prepare a compelling business case showing the costs of not moving ahead with our strategy.

d. Prepare a theory of change (impact pathway) for the coalition showing the phased outcomes expected and the partners to be engaged (including the role of advocacy in creating an enabling policy environment).

e. Develop options for partnerships in medium and longer term linked to landscape analysis and foresight studies.

\section{MEDIUM-TERM ACTIONS (5-10 YEARS)}

\section{VIRUSES}

a. Establish an on-line updated global virus cassava database.

b. Raise awareness of farmers, NGOs, extension workers and all stakeholders about new spread of viruses.

c. Strengthen capacity of all cassava stakeholders in understanding, responding to and managing virus diseases.

\section{WHITEFLIES}

a. Apply new knowledge of flora around cassava fields that promote natural enemy activity in developing improved whitefly IPM strategies.

b. Multiply and disseminate exotic parasitoids to better control whitefly.

c. Evaluate whitefly-resistant transgenic varieties and determine effects on the natural enemy fauna.

d. Strengthen control of super-abundant whiteflies in newly-threatened areas through the deployment and dissemination of whitefly-resistant varieties.

e. Disseminate IPM strategies for whitefly control throughout affected countries.

f. Strengthen human capacity through postgraduate studentships and technical training for extension teams.

\section{CLIMATE CHANGE}

a. Develop a cassava mechanistic crop model for understanding relationship between crop and climate, capable of predicting yields for a range of varieties across a range of climate conditions.

b. Incorporate the results of the model into the mapping interface for decision makers to consult.

\section{BREEDING}

a. Develop a pre-emptive breeding programme for CBSD and whitefly resistance in West Africa, using centralized screening facilities based on regional and national action plans.

b. Develop a pre-emptive breeding programme against CMD, CBSD and whiteflies in the Americas and in Asia.

c. Deploy transgenic virus and whitefly resistant varieties in farmers' preferred cultivars, as a complement to conventional breeding in the threatened areas.

d. Identify new sources of virus and whitefly resistance in cultivated and wild germplasm.

\section{SEED SYSTEMS}

a. In disease endemic zones, build the capacity of commercially-independent cassava stem producers (using where possible a combination of tissue culture virus-indexed material and low/no disease foundation material).

b. Develope farmer centric quality stem standards based on degeneration evidence / farmer willingness to pay for disease free / low disease planting material. c. Strengthen small and medium enterprises in community-based seed processing, putting pressure on cassava producers to promote disease tolerant planting material and adherence to quality stem standards.

CAPACITY BUILDING

a. Build new facilities to participate in the different types of actions: laboratories, multiplication and propagation centres, quarantines...

b. Forge the next generation of technicians and scientists to participate in the war on cassava viruses.

c. Develop short-term courses to continuously train the necessary personnel to perform all the tasks from surveillance to seed systems.

POLICY MAKERS, ADVOCACY

a. Make use of bank of advocacy and knowledge management material for communications.

b. Use ex-poste impact assessments of immediate actions and refined ex-ante assessments of planned future actions to strengthen case for sustained and expanded interventions.

c. Identify stakeholder beneficiaries of immediate actions to lead advocacy efforts for sustained efforts to tackle cassava virus pandemics.

\section{STRATEGY}

a. Coordinate all activities to make sure that gaps are filled and actions are taken.

b. Conduct regular meetings at the regional and global levels to review projects, progress and problems.

c. Monitor progress in a coordinated manner, and provide feedback to all partners. 
Table 1 (continued)

\section{LONG-TERM ACTIONS (11-20 YEARS)}

\section{VIRUSES}

a. Constitute virus culture repositories / collection centers.

b. Develop a global virus alert network.

\section{WHITEFLIES}

a. Model the impact of climate change on whiteflies and their natural enemies and develop strategies to mitigate any negative impacts on whitefly control.

b. Deploy whitefly-resistant transgenic varieties.

c. Incorporate novel control tactics into whitefly IPM strategies.

d. Extend the dissemination of whitefly IPM strategies for commercial cassava growers to take into account the increasing commercial development of the cassava crop in Africa.

e. Document whitefly control impacts.

\section{CLIMATE CHANGE}

a. Production of large datasets into a cassava online interface, based on field measurement of pest/disease prevalence and impact to generate robust statistical relationships.

b. Incorporate the results into the cassava online interface.

\section{BREEDING}

a. Deploy varieties resulting from new genomic selection, with resistance to $\mathrm{CMD} / \mathrm{CBSD} /$ whiteflies and also farmers' preferred agronomic, cooking and organoleptic traits.

b. Use fine mapping to transfer identified genes of resistance to farmers' preferred cultivars.

c. Understand genetic effects on molecular resistance mechanisms through comparative genomics.

d. Understand and use resistance via gene editing techniques.

e. Discovery of allelic variance in genebanks through sequencing, and assessing dosage effects in polyploidy.

\section{SEED SYSTEMS}

a. Establish a multi-national farmer owned cooperative of decentralized stem and mini-stem producers capable of exercising lobbying authority and influence on both research and national governments.

\section{CAPACITY BUILDING}

a. Create and organize complete cassava courses comprising virology, entomology, breeding, virus control, development, seed quality control, regulation and commercialization of quality seeds...

\section{POLICY-MAKERS, ADVOCACY}

a. Continue medium term actions

STRATEGY

a. Continue medium term actions

Table 2 Prioritizing the major activities of the Road Map's War on Cassava Viruses in Africa

Priority 1: Contain CBSD in East Africa and prevent its spread in the rest of the African continent:

- Raise awareness of the risks of inter-country exchange of cassava planting material — from policymakers to farmers.

- Mount country-level surveillance and monitoring networks to detect super-abundant whiteflies and the CBSD.

- Eradicate the whiteflies and the CBSD-infected plants when localized in new territories.

- Introduce best CBSD-tolerant cassava cultivars from East Africa to West Africa to be deployed immediately after identifying the presence of CBSD in Central and West African countries.

- Educate high-level policymakers to support the initiatives and establish and link national task forces on CBSD and super-abundant whiteflies.

\section{Priority 2: Eliminate or decrease the impact of both CBSD and CMD:}

- Prioritize target zones for intervention based on existing data and new surveillance information.

- Promote the establishment of seed systems involving public and private sectors and local communities for virus-free propagation of resistant cassava material.

- Develop farmer-preferred cassava cultivars resistant to all viruses and whiteflies.

- Develop and implement whitefly management using biological control, and rational chemical use for clean seed sites.

Priority 3: Prevent the spread of whiteflies and cassava viruses globally:

- Strengthen controls on movement of cassava cultivars across continents.

- Update the guidelines for safe movement of cassava cultivars.

- Raise awareness of the risks of movement of cassava cultivars across continents - from policymakers to farmers.

- Strengthen capacities of national plant protection organizations in Asia, Africa, and South America.

- Develop pre-emptive breeding for CMD and CBSD in Latin America and Asia. 


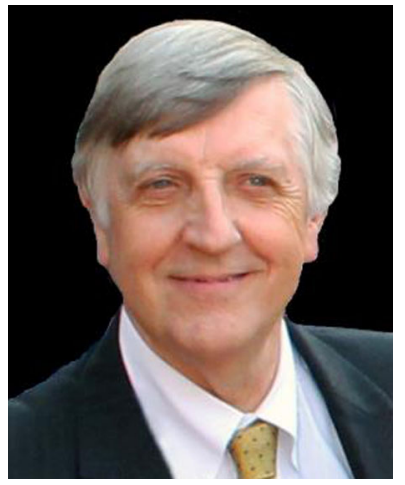

Claude Fauquet received his Ph.D. in biochemistry from University Louis Pasteur in Strasburg, France in 1974. Dr. Fauquet joined the Institut de Recherche pour le Développement, as a plant virologist for 28 years, and served in Ivory Coast, West Africa for 14 years. In 1991, he co-founded the International Laboratory for Tropical Agricultural Biotechnology (ILTAB) at The Scripps Research Institute, California. ILTAB was hosted by the Donald Danforth Plant Science Center, St. Louis, MO, from 1999 to 2012. He also is a co-founder of the Global Cassava Partnership for the 21st Century (GCP21) in 2002, which he is now directing and whose goal is to improve cassava worldwide.

Dr. Fauquet is an international leader in plant virology including taxonomy, epidemiology, molecular virology, and in gene-silencing as an antiviral strategy.

In 2005 he developed the project called Virus Resistance Cassava in Africa (VIRCA), aiming at developing cassava commercial products for poor farmers in Africa and the first product is scheduled to be delivered to East African farmers by 2017. He was Secretary of the ICTV (International Committee on Taxonomy of Viruses) for 18 years and the editor of several Reports including the VIIIth ICTV Report. He published more than 300 research papers in reviewed journals and books. He is a fellow of the American Association for the Advancement of Science, of the American Phytopathological Society and a member of the St Louis Academy of Sciences. In 2007, Dr. Fauquet was knighted "Chevalier de l'Ordre des Palmes Académiques" by the French Minister of High Education and Research

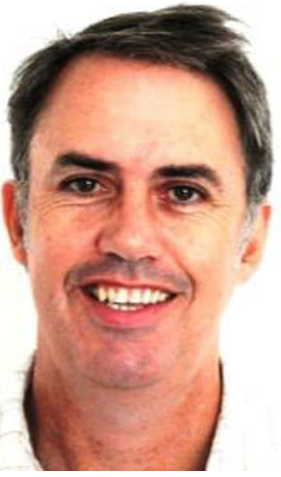

James Legg James Legg is a scientist at the International Institute of Tropical Agriculture (IITA), with more than 20 years experience of experience on plant viruses and their insect vectors. Most of James' professional career has focused on strengthening understanding of cassava viruses, and through this to develop and facilitate the promotion of control strategies. In addition to playing a direct active role in research, James has also contributed to strengthening African science capacity through producing training materials, leading training workshops and supervising post-graduate students. James has been based at IITA's East Africa hub in Dar es Salaam, Tanzania, for the last seven years, and he has been involved in running several regional research projects focused on cassava viruses, their whitefly vectors and the development and implementation of sustainable seed systems. James currently leads the pests and diseases theme of the Roots, Tubers and Bananas (RTB) Programme of the Consultative Group on International Agricultural Research (CGIAR).

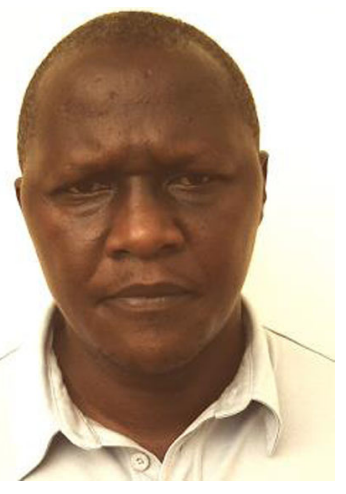

Pheneas Natwuruhunga graduated from Makerere University with a $\mathrm{Ph} . \mathrm{D}$. degree in Agronomy Sciences and, from the University of Ibadan, Nigeria with an M.Sc. in Agronomy, majoring in breeding. He has over 24 years' experience in root crops research and over 10 years' experience in coordinating regional root crops research networks in East and Southern Africa, respectively. $\mathrm{He}$ was the national team leader of the Rwanda cassava national program where he developed improved varieties highly resistant to disease.

After his $\mathrm{PhD}$ he joined IITA in Eastern Africa to mitigate cassava mosaic disease (CMD) by developing and deploying resistant cassava materials in the region while coordinating the Eastern Africa Root Crop Research Network (EARRNET) working in collaboration with the National Agriculture Systems Programs (NARS) under the Association of Agricultural ASARECA. He initiated the conventional breeding work resistance to on cassava brown streak in Uganda. In 2009 he coordinated the Southern Africa Root Crops Research Network (SARRNET) under the Southern Africa Development Community (SADC). He has more than 40 peer-reviewed scientific publications and conference papers. He is currently the cassava regional breeder in the Southern Africa Region based at IITA-Malawi. He participated in developing and led different regional cassava value chain projects. Presently, he is the Secretary General of the International Society of Tropical Root Crops-Africa Branch (ISTRC-AB).

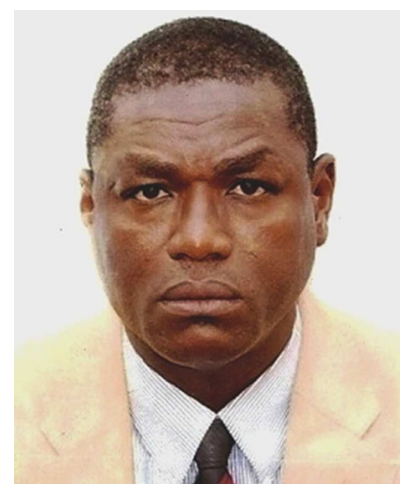

Emmanuel Okogbenin

Emmanuel Okogbenin is a welltrained scientist in plant breeding, genetics, and genomics with good background in agronomy, and physiology. He has immense working experience in both international agricultural research (IAR) and NARS.

Emmanuel was a pioneer scientist in cassava biotechnology research. He led the marker assisted breeding (MAS) initiative for cassava mosaic disease (CMD) resistance in NARS resulting in the release of the first CMD resistant Latin American Cassava varieties in Africa.

He pioneered Marker-Assisted Recurrent Selection (MARS) for drought tolerance and improved productivity of cassava in marginal drought prone ecologies in Africa, He has held several key positions in his professional career including:- Head, CIAT/IITA collaboration unit at IITA, Head of the Molecular breeding unit, NRCRI, Product Delivery Coordinator for cassava in the CGIARGCP, Leader of Cassava Transformation breeding at FMARD, Nigeria, Lead and PI of several international and national projects. Through the project activities he was involved in, he has significantly contributed to the development of commercialization roadmaps as well as capacity building on biosafety for key NARS personnel in Africa. He also served as a consultant to international organizations such as IAEA and FAO.

Dr. Okogbenin's publications include journal articles, book chapters and conference papers presented at international and national meetings. Dr. Emmanuel Okogbenin is presently the Director of Technical Operations at the African Agricultural Technology Foundation (AATF). 


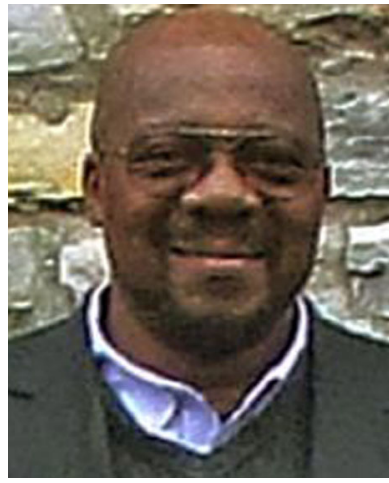

Eugene Terry was born in Sierra Leone and received his higher education in Canada - B.Sc Agriculture and M.Sc Plant Pathology from McGill University, and Doctorate in Plant Pathology from the University of Illinois UrbanaChampaign. Eugene has held senior research and institutional leadership positions in regional and international institutions first at the International Institute of Tropical Agriculture (IITA) in Nigeria as Plant Pathologist and later Director of International Programs; at the West Africa Rice Development Association (WARDA now AfricaRice) as Director General 1987-1996; as Crops Advisor to the Director Agriculture and Rural Development, The World Bank 19962002; and as the Founding Director of the African Agricultural Technology Foundation (AATF), Nairobi , 2002-2004.

Eugene was awarded the Presidential (Mali Government) Award for Outstanding Contribution to Rice Science in Africa; and the Macdonald College McGill University Distinguished Alumni 2012 Award.

Eugene has extensive knowledge and experience in Cassava Improvement in Africa.

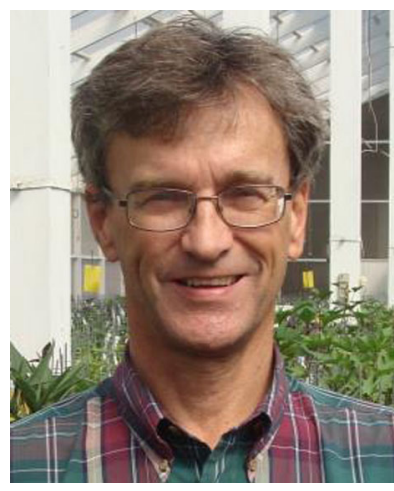

Graham Thiele Graham Thiele is leading the CGIAR Research Program on Roots, Tubersand Bananas which brings together multiple partners to improve food security and reduce rural poverty through research for development. He provides intellectual leadership to develop a shared vision, build a strong partnership among participating centers, partners and other stakeholders and manages for outcomes.

Graham Thiele is a UK national, with an MSc in Agricultural Economics and a PhD in Anthropology from London and Cambridge Universities, respectively. He began his career at DFID in 1984 working on market opportunity studies, farming systems research, and research-extension liaison. He joined CIP in 1994, contributing to developing, testing, and disseminating approaches for promoting innovation in value chains through public private partnerships, participatory varietal selection and seed system development. In 2005, he became the leader of CIP's Social and Health Sciences Division guiding work on targeting, priority setting, and impact and adoption studies of new agricultural technology and participatory methods. He has mentored and backstopped projects and scientists in Bolivia, Peru, Ecuador, Benin, Kenya, Rwanda, Tanzania, the Philippines, and Indonesia. He has authored over 60 peer-reviewed articles, two books, numerous book chapters and magazine pieces.

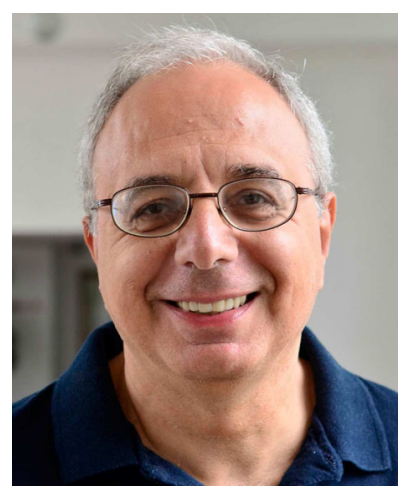

Joe Tohme Joe Tohme received his $\mathrm{PhD}$ in Crop Sciences from Michigan State University. He has worked as a plant geneticist at the International Center for Tropical Agriculture (CIAT) in Cali, Colombia since 1987. $\mathrm{He}$ is currently the CIAT Agrobiodiversity Research Director coordinating teams that include the Genetic Resources Unit, the biotechnology, bean, cassava, forage and rice programs. The multidisciplinary teams work in fields as diverse as breeding, plant pathology, entomology, plant physiology, molecular biology, bioinformatics, genetic transformation and seed systems.

In addition, Dr. Tohme coordinates the biotechnology activities of HarvestPlus, an international research program that seeks to reduce micronutrient malnutrition by harnessing the powers of agriculture and nutrition research to breed nutrient- dense staple foods. HarvestPlus is co-organized by CIAT and the International Food Policy Research Institute (IFPRI) based in Washington, D.C. $\mathrm{He}$ is the Co-founder with Dr. Claude Fauquet of the Global Cassava Partnership. Dr. Tohme's research involves integrating genomicsmolecular- assisted selection with breeding and germplasm conservation activities; setting up gene expression and SNP facilities; and gene discovery for abiotic and nutritional traits. 